\title{
Cohort study of effect of vaccination on pancreas disease in Norwegian salmon aquaculture
}

\author{
Britt Bang Jensen ${ }^{1, *}$ Anja B. Kristoffersen ${ }^{1,2}$, Camilla Myr ${ }^{3}$, Edgar Brun ${ }^{1}$ \\ ${ }^{1}$ Section for Epidemiology, Norwegian Veterinary Institute, 0106 Oslo, Norway \\ ${ }^{2}$ Department of Informatics, University of Oslo, PO Box 1080, Blindern 0316 Oslo, Norway \\ ${ }^{3}$ PD-free Project/The Norwegian Seafood Research Fund, 5035 Sandviken, Norway
}

\begin{abstract}
Pancreas disease (PD) is an economically important viral disease in Norwegian aquaculture, with 75 to 89 annual outbreaks from 2009 to 2011. To hinder further spread of disease from an initial endemic area on the west coast of Norway, measures for surveillance and control are in place, and the disease is notifiable on a national level. Since 2008, the Norwegian coastline has been divided into 2 administrative zones separated by a production-free area of 10 nautical miles at approximately $63^{\circ} \mathrm{N}$. At the same time, a vaccination program involving most marine salmonid farms was initiated by the industry, using a vaccine against PD that was made commercially available in 2007 . The effects of the vaccine in the field have been questioned, since the annual number of PD outbreaks has not decreased as expected. However, other production parameters can be used for evaluation of vaccine effect, and in this study the effects of vaccination on cumulative mortality, growth rate, feed conversion factor and number of discarded fish were analyzed using data collected from fish cohorts with and without PD put to sea between spring 2007 and spring 2009. The results show that vaccination against PD has a positive effect in reducing the number of outbreaks, and decreasing cumulative mortality and the number of fish discarded at slaughter.
\end{abstract}

KEY WORDS: PVD · Atlantic salmon · Salmonid alphavirus · Vaccine evaluation · Field study Resale or republication not permitted without written consent of the publisher

\section{INTRODUCTION}

Pancreas disease (PD) was first diagnosed in Norway in the mid 1980s (Poppe et al. 1989). During the first decade less than 5 outbreaks were reported per year. These outbreaks were restricted to a stretch of coastline of approximately $160 \mathrm{~km}$ on the southwest coast of Norway. After 1996 the number of outbreaks began to increase, and by 2003 over 20 outbreaks were reported annually. The geographic distribution also expanded north and south of the core area with a few outbreaks in the northern part of the country (Fig. 1). The yearly total number of outbreaks including both Atlantic salmon Salmo salar and rainbow trout Oncorhynchus mykiss doubled from 2003 to
2004, and from 2005 to 2007. In 2007 the number of outbreaks was nearly 100 (Fig. 1). The highest number so far was reached in 2008, with 108 outbreaks. Thereafter the annual number of outbreaks fell to 75 , 88 and 89 in 2009, 2010 and 2011, respectively. The number of active sites was comparable for 2007 to 2010 (between 776 and 795) and increased to 810 in 2011. Thus, the proportion of infected versus noninfected sites has been stable, between 10 and $14 \%$.

The rapid increase in number of PD outbreaks and expansion of the PD-affected area has caused concern among the Norwegian salmon producers and the authorities. In 2007, the authorities placed infection with PD virus on the national list of notifiable diseases, thus requiring any suspicion or diagnosis of 

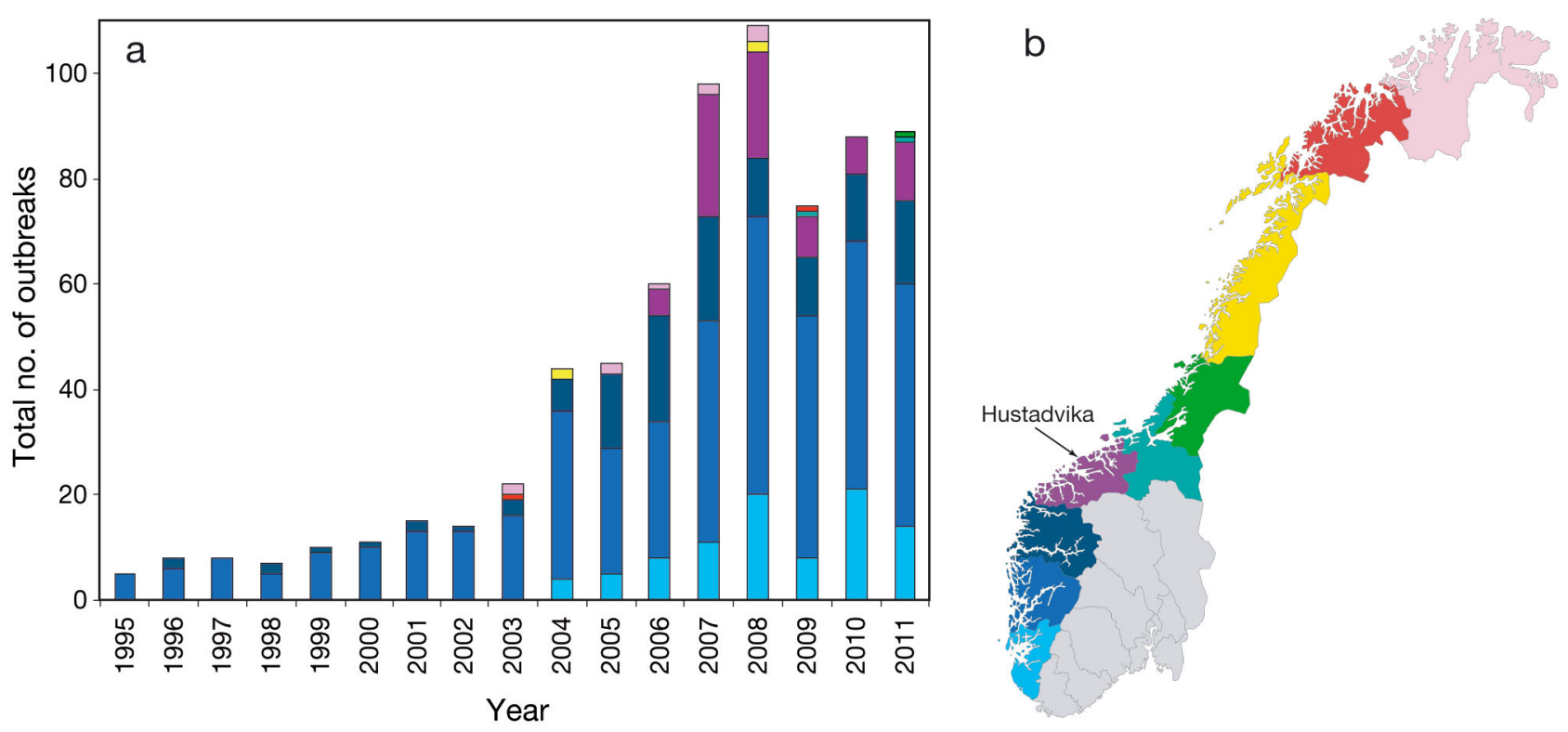

Fig. 1. Salmo salar. (a) Annual number of all outbreaks of pancreas disease between 1995 and 2011, divided by counties. (b) Location of each county, with colours corresponding to the graph (data collected by the Norwegian Veterinary Institute). No pancreas disease has been reported in counties shown in grey

PD to be reported to the competent authority (FKD 2008). Because the prevalence of PD differed on different parts of the coast, the regulation divided the coastline into 2 administrative units north and south of Hustadvika, a 10 nautical mile open and weatherexposed section of coastline (approx. $63^{\circ} \mathrm{N}$ ) with no fish farms (Fig. 1). This section of coast is assumed to act as an efficient barrier between an endemic south region and a disease-free north region. Any diagnosis of PD north of Hustadvika is followed by immediate destruction of fish, disinfection and fallowing. In the area south of Hustadvika, considered to be endemic for $\mathrm{PD}$, a regime was implemented with (1) mandatory testing for PD-virus before any transportation, (2) prohibition of movements out of the area of any fish with suspicion of PD, PD-virus detection or of diseased fish, (3) publicly available maps showing current outbreaks, and (4) disinfection and fallowing of farms after a production cycle where the fish contracted PD (FKD 2007).

In autumn 2007, a commercial vaccine against PD was made available on the market (Norvax ${ }^{\circledR}$ Compact $\mathrm{PD}$, Intervet International B.V.). This vaccine is based on inactivated PD virus and a reduction in mortality of at least $50 \%$ is claimed in comparisons of vaccinated fish against unvaccinated fish at the same farm (Norvax 2009).

In addition to adhering to the control measures imposed by the authorities, the industry established a project (the 'PD-Free' project) in 2008 with the spe- cific aims to (1) reduce losses due to $\mathrm{PD}$, (2) reduce the number of PD outbreaks, (3) stop further spread of PD and (4) develop a more robust and sustainable production. The means agreed on to achieve these aims were to more efficiently utilise good sea locations and abandon less suitable ones, coordinate sea transfer of same generations, and implement PD vaccination of all salmon cohorts put to sea. Almost $100 \%$ of the concessions within the endemic area were represented in the project.

Subsequently, the effect of PD vaccination has been questioned by the industry. The main criticism is that vaccination of fish does not prevent disease; many farms experience PD outbreaks despite vaccinating their fish. The annual number of outbreaks did decrease by 18 to $30 \%$ (see above) after the introduction of vaccination but has stagnated in more recent years. The number of annual outbreaks has been used as a measure of the effect of vaccination, whereas the effect of vaccination on other production outcomes such as mortality and growth has not been evaluated.

Hence, the purpose of the present study was to evaluate the effect of vaccination against PD, using several different production factors as measures and controlling for other risk factors that are believed to be important for occurrence of PD by including them in multivariable regression models. With the aid of the PD-free project, data were obtained from cohorts in the field. 


\section{MATERIALS AND METHODS}

\section{Study population and data collection}

The study population was Atlantic salmon smolt cohorts put to sea between spring 2007 and spring 2009 and slaughtered before mid-February 2011. A cohort was defined as all smolt put to sea at one site and followed from sea transfer through to slaughter. Cohorts at the same site were separated by fallowing and there were no overlapping cohorts at any site. Cohorts were split into spring smolt cohorts, autumn smolt cohorts, mixed cohorts or relocated cohorts (Cohort index) as described in Kristoffersen et al. (2009; section 2.3).

A questionnaire was sent to all concessions that were part of the PD-free project at the end of the project period and followed up by telephone calls and personal visits to clarify questions and collect answers. Participation in the study was voluntary, and of the 37 companies contacted, completed questionnaires were received from $26(70 \%)$. These questionnaires covered data from 202 cohorts, 4 of which did not include vaccination status for $\mathrm{PD}$, hence the number of cohorts included in the study was 198 . This comprised $53 \%$ of all actively farmed Atlantic salmon cohorts in the endemic area during the study period. Of these, $56 \%$ experienced a PD outbreak, whereas $62 \%$ of cohorts not included in the study experienced a PD outbreak.

All vaccinated cohorts were vaccinated with the same type of vaccine, following the same procedure regarding dose, administration route and frequency, as there was only one commercial vaccine available (see 'Introduction'). Fish are normally vaccinated at 40 to $60 \mathrm{~g}$ and transferred to the sea at 80 to $100 \mathrm{~g}$.

\section{Description of data}

The questionnaire collected data on management, health and slaughter variables registered by the companies during the production cycle.

The variables included in the study are described in Table 1. Data on disease outbreaks were collated by the Norwegian Veterinary Institute (NVI).

\section{PD case definition}

A list of PD outbreaks within the study period was collated by the NVI, which keeps records of all PD outbreaks reported to the Norwegian Food Safety Authority (NFSA). NVI uses the following definitions to diagnose PD. Clinical signs (increased mortality, reduced feed intake) and a positive result of PCRscreening for PD virus results in a suspected PD diagnosis. Confirmation of PD requires that pathological changes consistent with PD are also demonstrated on fish from the same batch. Screening programs for PD virus are in place for most of the companies that operate in the PD-endemic area, and positive virus findings must be reported to the authorities, regardless of whether they are accompanied by clinical signs. Therefore the list of cases includes both cohorts where increased mortality led to suspicion of PD and some which were discovered as a result of screening. In this study, both suspected and confirmed cases were included. A PD case cohort is thus a cohort that obtained a PD diagnosis sometime during the cohort's lifespan, whereas a control cohort is a cohort in which PD had never been diagnosed.

\section{Other disease outbreaks}

A list of reported heart and skeletal muscle inflammation (HSMI) and cardiomyopathy syndrome (CMS) outbreaks was retrieved by the NVI. Like PD, HSMI is a notifiable disease, whereas CMS is not. However, any case of increased mortality (defined as mortality which is significantly higher than what is considered normal for the farm, FKD 2008) must be reported to NFSA, and thus the CMS data were expected to be reasonably exhaustive. As HSMI and CMS have comparable pathology, the 2 diseases were grouped together for the purpose of investigating the connection between other infectious heart conditions and PD and their effect on production outcomes. A cohort was thus assigned the value ' 1 ' if either HSMI or CMS was diagnosed sometime during the cohort's lifespan, and the value ' 0 ' if neither of these diseases were ever diagnosed on the cohort.

Infectious pancreatic necrosis (IPN) is a widespread disease in Norwegian salmon aquaculture, and several laboratories offer testing for IPN. Therefore, information on this disease was obtained from the questionnaire sent to the concessions. Diagnosis of IPN is based on clinical suspicion, followed by confirmation of virus by immunohistochemistry, PCR or antibody-induced agglutination. Finally, the recipients were asked to indicate whether or not the cohort had suffered from gill inflammation during the production period. Gill inflammation is considered to have a multifactorial origin, and is diagnosed by pathological lesions observed in histopathology. 
Table 1. Salmo salar. Descriptive statistics for the potential risk factor variables for cohorts with and without pancreas disease (PD). PD case cohorts were diagnosed with PD sometime during their lifespan; control cohorts never had a PD diagnosis. Most of the cohorts had either no vaccinated fish or all fish vaccinated, except for 20 cohorts that had between 20 and $95 \%$ of fish vaccinated; a cohort was considered vaccinated if $>0 \%$ of the fish were vaccinated. For other diseases (IPN, HSMI/CMS, gill inflammation) a cohort was considered positive if the disease was reported any time during the cohort's lifespan. Cohort index indicates when a cohort was transferred to the sea: as spring smolt cohorts, autumn smolt cohorts, mixed cohorts or relocated cohorts. Results of single variable logistic regressions comparing each variable between case and control cohorts are shown.

HSMI: heart and skeletal muscle inflammation; CMS: cardiomyopathy syndrome; IPN: infectious pancreatic necrosis

\begin{tabular}{|c|c|c|c|c|c|c|}
\hline \multirow[t]{2}{*}{ Risk factor } & \multirow[t]{2}{*}{ Description } & \multicolumn{2}{|c|}{ Control cohorts -} & \multicolumn{2}{|c|}{ Case cohorts } & \multirow[t]{2}{*}{$\mathrm{p}$} \\
\hline & & No. not vacc. & No. vacc. & No. not vacc. & No. vacc. & \\
\hline PD vaccination & If $>0 \%$ of the fish were vaccinated & 23 & 64 & 52 & 59 & 0.004 \\
\hline & & No. negative & No. positive & No. negative & No. positive & \\
\hline IPN & See 'Other disease outbreaks' & 61 & 26 & 57 & 54 & 0.008 \\
\hline HSMI or CMS & See 'Other disease outbreaks' & 54 & 33 & 68 & 43 & 0.91 \\
\hline \multirow[t]{2}{*}{ Gill inflammation } & See 'Other disease outbreaks' & 67 & 20 & 83 & 28 & 0.71 \\
\hline & & Mean \pm SD & $90 \%$ range & Mean \pm SD & $90 \%$ range & \\
\hline Infection pressure $\left(\mathrm{km}^{-1}\right)$ & See 'Infection pressure' & $0.12 \pm 0.17$ & $0.005-0.35$ & $0.18 \pm 0.20$ & $0.004-0.62$ & 0.016 \\
\hline No. of fish $\left(10^{6}\right)$ & $\begin{array}{l}\text { Total no. of fish put to sea } \\
\text { during the production period }\end{array}$ & $0.72 \pm 0.38$ & $0.20-1.31$ & $0.78 \pm 0.29$ & $0.29-1.25$ & 0.28 \\
\hline \multirow[t]{2}{*}{ Density (ind. $\mathrm{m}^{-3}$ ) } & $\begin{array}{l}\text { Total number of fish divided } \\
\text { by the total pen volume }\end{array}$ & $5.3 \pm 4.4$ & $2.4-9.5$ & $6.6 \pm 6.8$ & $2.6-13.3$ & 0.15 \\
\hline & & \multicolumn{2}{|c|}{ No. of cohorts } & \multicolumn{2}{|c|}{ No. of cohorts } & \\
\hline \multicolumn{7}{|l|}{ Cohort index } \\
\hline Spring smolt & As described in & 45 & & 48 & & 0.23 \\
\hline Autumn smolt & Kristoffersen et al. (2009); & 22 & & 34 & & 0.41 \\
\hline Mixed & see 'Statistical modeling & 2 & & 4 & & 0.6 \\
\hline \multirow[t]{2}{*}{ Relocated } & approach' & 18 & & 25 & & 0.76 \\
\hline & & Mean \pm SD & $90 \%$ range & Mean $\pm \mathrm{SD}$ & $90 \%$ range & \\
\hline Cumulative mortality & $\begin{array}{l}\text { Total number of dead fish as } \\
\text { percentage of total number of fish }\end{array}$ & $11.7 \pm 8.7$ & $2.6-29.2$ & $22.6 \pm 13.2$ & $5.5-46.7$ & $<0.001$ \\
\hline Growth rate & $\begin{array}{l}\text { Average growth per day } \\
\text { in percent }\end{array}$ & $0.77 \pm 0.08$ & $0.62-0.87$ & $0.72 \pm 0.11$ & $0.58-0.88$ & $<0.001$ \\
\hline Feed factor & $\begin{array}{l}\text { Kg feed per kg increase } \\
\text { in biomass }\end{array}$ & $1.16 \pm 0.06$ & $1.08-1.27$ & $1.2 \pm 0.08$ & $1.10-1.35$ & 0.002 \\
\hline Discarded & $\begin{array}{l}\text { Percentage of fish that were } \\
\text { discarded at slaughter, of total } \\
\text { delivered to processing plant }\end{array}$ & $1.3 \pm 1.7$ & $0.1-4.0$ & $2.2 \pm 2.3$ & $0.4-5.6$ & 0.006 \\
\hline
\end{tabular}

\section{Infection pressure}

Previous studies have shown that infection pressure has a strong effect on the probability of PD outbreak (Kristoffersen et al. 2009, Viljugrein et al. 2009). Infection pressure reflects the amount of infection each cohort experiences from surrounding cohorts in a neighborhood, so risk of PD infection on a site is assumed to be related to presence of PD on neighboring sites. Infection pressure can be modeled in different ways; all the models described in Viljugrein et al. (2009) were tested in the mixed-effects logistic regression model (see 'Statistical modeling approach') with neighborhoods of 5, 10, 25, 50 or $100 \mathrm{~km}$, both linearly and loglinearly. The infection pressure model that provided the best univariate description of PD cases was chosen. The infection pressure model that best described PD cases included presence of a PD case cohort within a $25 \mathrm{~km}$ seaway distance, modelled as the reciprocal squared seaway distance between the 2 cohorts. For each cohort the influence from every PD case cohort in the neighborhood is summed:

$$
i p_{i}(t)=\sum_{j \in N_{i}} \frac{I_{j}(t)}{d_{i j}^{2}}
$$

where $I_{j}(t)$ has the value 1 from 2 mo before PD is detected until the fish are slaughtered on farm $j, d_{i j}$ is the seaway distance between cohort $i$ and cohort $j$, and $\mathrm{N}_{i}$ consist of all cohorts in the 25 seaway $\mathrm{km}$ neighborhood of cohort $i$. 


\section{Statistical modeling approach}

The association between the probability of a PD outbreak and PD vaccination was evaluated using a multivariable analysis including the 8 first risk factors described in Table 1. A mixed-effects logistic regression model using glmmPQL from the library MASS in R (Venables \& Ripley 2002) was applied. For the infection pressure variable, log-linear transformation was used. Generation was included as a random effect to test for possible confounding, as more cohorts were vaccinated in the later generations compared to earlier (Table 2). The area under a receiver-operator (ROC) curve (AUC) was used to measure the accuracy of the model.

The continuous response variables - cumulative mortality, growth rate, feed factor and number of discarded fish - were all modeled with linear mixedeffects models accounting for the different random effects of the different year classes using lme from the package nlme in R (Pinheiro et al. 2010). To verify if the vaccination had any effects on the PD cases, mixed-effect models were also used to model the continual response variables for only the cohorts that developed $\mathrm{PD}$. Model selection was done by backward selection using the Akaike information criterion (AIC) as a comparison measure. AIC value differences of \pm 2 are considered to represent equally good models (Duong 1984), and in these cases the simplest model is reported. The data set had some missing values for some of the variables, therefore it was always restricted to the largest data set including no missing values for the variables in the comparison when comparing AIC values. Residuals were inspected visually by normal quantile-quantile plots, plots of residuals against response and boxplots of the residuals for each generation. To evaluate the proportion of vari-

Table 2. Salmo salar. Number of cohorts included in the study and number of cohorts that developed pancreas disease (PD) during the cohort lifespan. Total number of vaccinated cohorts and how many of these that developed PD per generation is also shown

\begin{tabular}{|lcccc|}
\hline $\begin{array}{l}\text { Sampling } \\
\text { period }\end{array}$ & $\begin{array}{c}\text { No. of } \\
\text { cohorts }\end{array}$ & $\begin{array}{c}\text { No. of PD } \\
\text { cohorts }\end{array}$ & $\begin{array}{c}\text { No. of } \\
\text { vaccinated } \\
\text { cohorts }\end{array}$ & $\begin{array}{c}\text { No. of vaccinated } \\
\text { cohorts with } \\
\text { PD outbreak }\end{array}$ \\
\hline Spring 2007 & 39 & 24 & 8 & 2 \\
Fall 2007 & 35 & 23 & 10 & 5 \\
Spring 2008 & 45 & 21 & 27 & 9 \\
Fall 2008 & 43 & 22 & 42 & 22 \\
Spring 2009 & 36 & 21 & 36 & 21 \\
Total & 198 & 111 & 123 & 59 \\
\hline
\end{tabular}

ance accounted for by the random effect in the mixedeffect models, an intraclass correlation coefficient (ICC) was calculated as variance of the random effect divided by the variance of the random effect plus the variance of the residuals (Stanish \& Taylor 1983). All models were also tested on data from only the 3 first generations (spring 2007 to spring 2008) where the number of farms using vaccination was less than for the last 2 generations (fall 2008 and spring 2009). This result is reported in Tables $\mathrm{S} 1 \& \mathrm{~S} 2$ in the supplement at www.int-res.com/articles/suppl/d102p023_supp.pdf.

\section{RESULTS}

\section{Descriptive statistics}

The data set consisted of a total of 198 cohorts, of which 111 developed PD during the cohort lifespan. The cohorts were distributed over 170 locations. The cohorts were mapped in order to visualize their geographic spread; visual inspection confirmed that they are evenly distributed within the endemic zone (Fig. S1 in the supplement). Each cohort belonged to 1 of 5 generations as shown in Table 2. The mean time from introduction into the marine phase to PD diagnosis was 9 mo with 5 and $95 \%$ percentiles of 2.8 and 16 mo respectively.

The mean cumulative mortality for PD case cohorts was $22.6 \%$, compared to $11.7 \%$ for the control cohorts (Table 1). Mean growth rate, feed factor and percentage of discarded fish for PD case cohorts and controls can all be seen in Table 1.

For the outcome variables cumulative mortality, growth rate and percentage of discarded fish, vaccination had a significant effect when analyzed in a univariate analysis. The mean cumulative mortality was $22.5 \%$ for non-vaccinated cohorts and $15.0 \%$ for vaccinated cohorts. The growth rate increased from 0.72 to $0.75 \%$ when cohorts were vaccinated, and the percentage of discarded fish was reduced from 2.74 to $1.28 \%$ (Table 3 ).

Even though the $90 \%$ range of the growth rate was almost similar for the control and case cohorts, the mean was different and the cumulative distribution (data not shown) also confirmed that control cohorts overall had a higher growth rate than case cohorts.

\section{Risk factors for PD outbreak}

The explanatory variables that had an effect on the probability of PD outbreak were PD vaccination, 
Table 3. Salmo salar. Summary of descriptive statistics for the 4 response variables used to analyse production loss for nonvaccinated and vaccinated cohorts. The results of single variable logistic regressions are summarised by $p$-value

\begin{tabular}{|lrrrrr|}
\hline \multirow{2}{*}{ Risk factor variables } & \multicolumn{2}{c}{ Non-vaccinated cohorts } & \multicolumn{2}{c}{ Vaccinated cohorts } & p \\
& Mean \pm SD & $90 \%$ range & Mean \pm SD & $90 \%$ range & $<$ \\
\hline Cumulative mortality & $22.5 \pm 12.6$ & $4.2-43.2$ & $15 \pm 11.9$ & $2.7-39.9$ & $<0.001$ \\
Growth rate & $0.72 \pm 0.11$ & $0.58-0.83$ & $0.75 \pm 0.1$ & $0.60-0.89$ & 0.036 \\
Feed factor & $1.18 \pm 0.07$ & $1.08-1.30$ & $1.19 \pm 0.07$ & $1.09-1.32$ & 0.36 \\
Discarded & $2.74 \pm 2.71$ & $0.60-7.50$ & $1.28 \pm 1.43$ & $0.10-3.70$ & $<0.001$ \\
\hline
\end{tabular}

IPN, infection pressure and cohort index (Table 4). If more than $0 \%$ of the fish in the cohort were vaccinated, the odds of PD outbreak was 3 times lower than that for cohorts with no vaccinated fish. The odds for PD outbreak were 2.7 times higher if the cohort had experienced IPN and increased from 1 to 1.61 when the infection pressure increased from 0.0 to 0.36 (Table 4). Spring smolt cohorts had half the probability of developing PD compared to other cohorts. The AUC for the ROC curve of the selected model was 0.72 .

The small intraclass correlation coefficient (ICC) shows that generation had very little effect on the results. When only the 3 first generations were analyzed separately the effect of PD vaccination was higher. The vaccinated cohorts had odds ratios that were 4 times lower and the spring smolt had odds ratios less than 2 times lower to suffer PD outbreak, while the effect of IPN and infection pressure was no longer included (supplement, Table S1).

Table 4. Parameter estimates and p-values from the mixedeffects logistic regression modeling the probability of an outbreak of pancreas disease (PD). The odds ratio (OR) for each estimate is provided. ICC: intraclass correlation coefficient; IPN: infectious pancreatic necrosis

\begin{tabular}{|lccc|}
\hline & Estimate & $\mathrm{p}$ & Odds ratio \\
\hline Intercept & 1.76 & 0.001 & \\
PD vaccination & -1.20 & 0.001 & 0.30 \\
IPN & 0.99 & 0.016 & 2.71 \\
log(infection & 0.30 & 0.010 & $\mathrm{a}$ \\
pressure+0.001) & & & \\
Spring smolt & -0.72 & 0.032 & 0.49 \\
SD random & 0.00010 & & \\
effect & & & \\
SD residuals & 0.99 & \\
ICC & $<0.001$ & \\
a The odds ratio of the infection pressure increased from 1 \\
to 1.49 when the infection pressure increased from 0 to \\
0.2 (75th percentile) and further to 1.61 when infection \\
pressure increased to 0.36 (90th percentile) \\
\hline
\end{tabular}

\section{Risk factors for production losses due to PD}

For this analysis, a linear mixed-effects model including generation as a random effect was developed both for all cohorts, and for the PD case cohorts only. Which explanatory variables were included and whether all cohorts were included or only PD case ones varied between the different response variables (Table 5). For all response variables, PD outbreak was an explanatory variable. PD vaccination had an effect on cumulative mortality and number of fish discarded when all cohorts were included in the model, but only on cumulative mortality when only PD case cohorts were analyzed.

The residuals for all models were inspected and were generally found to be close to normally distributed. These models were also tested on data excluding the last 2 generations (supplement, Table S2). The differences from the model including all generations were negligible, and thus only the model including all generations will be discussed.

\section{DISCUSSION}

The present study shows that there is a positive effect of the current vaccination protocol against PD in Norwegian salmon farming. Vaccination has reduced the number of outbreaks and has had a beneficial effect on 2 of the 4 other production factors tested (cumulative mortality and number of discarded fish at slaughter).

The study showed that the odds for PD outbreak were 3 times lower if the location had vaccinated fish. Conversely, the odds for PD outbreak were 2.7 times higher if the cohort had a history of IPN outbreak. From the available data, determining if IPN outbreaks preceded the PD-outbreak or vice versa was not possible. IPN most commonly occurs within a few weeks after sea transfer (Brun 2001). Even though PD can occur throughout the entire marine phase, in the present study it occurred on an average of 9 mo after 
Table 5. Salmo salar. Final models for the 4 response variables for all cohorts and for pancreas disease (PD) case cohorts only. The number of reports included in the model varies since not all response variables are reported for each cohort. ICC: intraclass correlation coefficient; HSMI: heart and skeletal muscle inflammation; CMS: cardiomyopathy syndrome; IPN: infectious pancreatic necrosis; na: not applicable; ni: not included because the Akaike's information criterion (AIC) value did not decrease; ns: not significant

\begin{tabular}{|c|c|c|c|c|c|c|}
\hline & \multicolumn{3}{|c|}{ All cohorts } & \multicolumn{3}{|c|}{ PD case cohorts } \\
\hline Cumulative mortality & $(\mathrm{n}=198)$ & & & $(n=111)$ & & \\
\hline Intercept & 15.1 & $(2.09)$ & $<0.001$ & 29.5 & $(2.02)$ & $<0.001$ \\
\hline $\mathrm{PD}$ & 8.66 & $(1.60)$ & $<0.001$ & na & & na \\
\hline PD vaccination & -5.85 & $(1.86)$ & 0.002 & -9.31 & $(2.36)$ & $<0.001$ \\
\hline IPN & 3.90 & (1.65) & 0.019 & ni & & ni \\
\hline HSMI or CMS & ni & & ni & -5.05 & $(2.42)$ & 0.040 \\
\hline Gill inflammation & 4.79 & $(1.83)$ & 0.010 & ni & & ni \\
\hline SD random effect & 1.85 & & & 0.0014 & & \\
\hline SD residuals & 10.6 & & & 12.4 & & \\
\hline ICC & 0.03 & & & $<0.001$ & & \\
\hline Growth rate & $(n=187)$ & & & $(n=106)$ & & \\
\hline Intercept & 0.80 & $(0.02)$ & $<0.001$ & 0.74 & $(0.02)$ & $<0.001$ \\
\hline $\mathrm{PD}$ & -0.048 & $(0.015)$ & 0.001 & na & & na \\
\hline HSMI or CMS & -0.033 & $(0.015)$ & 0.029 & ns & & ni \\
\hline Density & -0.003 & $(0.001)$ & 0.005 & -0.0041 & $(0.002)$ & 0.009 \\
\hline SD random effect & 0.020 & & & 0.022 & & \\
\hline SD residuals & 0.099 & & & 0.11 & & \\
\hline ICC & 0.05 & & & 0.04 & & \\
\hline Feed factor & $(n=198)$ & & & $(n=111)$ & & \\
\hline Intercept & 1.19 & $(0.011)$ & $<0.001$ & 1.20 & $(0.01)$ & $<0.001$ \\
\hline $\mathrm{PD}$ & 0.030 & $(0.009)$ & 0.001 & na & & na \\
\hline HSMI or CMS & -0.033 & $(0.009)$ & $<0.001$ & -0.044 & $(0.013)$ & 0.001 \\
\hline Gill inflammation & 0.024 & $(0.011)$ & 0.028 & 0.041 & $(0.016)$ & 0.011 \\
\hline $\log ($ infection pressure +0.001$)$ & 0.007 & $(0.003)$ & 0.036 & & & \\
\hline SD random effect & 0.022 & & & 0.025 & & \\
\hline $\mathrm{SD}$ residuals & 0.064 & & & 0.068 & & \\
\hline ICC & 0.11 & & & 0.12 & & \\
\hline No. of discarded fish & $(n=196)$ & & & $(n=110)$ & & \\
\hline Intercept & 2.13 & $(0.46)$ & $<0.001$ & 2.78 & $(0.55)$ & $<0.001$ \\
\hline $\mathrm{PD}$ & 0.67 & $(0.28)$ & 0.019 & na & & na \\
\hline PD vaccination & -1.13 & $(0.37)$ & 0.003 & $\mathrm{ni}$ & & ni \\
\hline SD random effect & 0.70 & & & 1.16 & & \\
\hline SD residuals & 1.90 & & & 2.09 & & \\
\hline ICC & 0.12 & & & 0.24 & & \\
\hline
\end{tabular}

sea transfer. Jansen et al. (2010) reported a mean of $53 \mathrm{wk}$, and thus the IPN outbreaks are assumed to have been preceded by PD outbreaks. The influence of previous IPN infection on subsequent PD outbreaks has not been investigated (Brun 2003), but the results presented here suggest that this effect should be explored.

Another effect was exerted by infection pressure, which could increase the odds for PD outbreak by as much as 1.61, if the infection pressure reached 0.36. The implications of this are discussed by Kristoffersen et al. (2009), who explain that having neighboring PD-infected sites increases the risk of contracting the disease, and thus in order to reduce number of outbreaks, the infection pressure must be reduced. How- ever, the effect of infection pressure was not strong in this study, and it disappears when the last 2 generations, where almost all cohorts were vaccinated, were excluded from the analysis. This suggests that infection pressure and vaccination might be inversely correlated and that the effect of vaccination is stronger than that of infection pressure.

Spring smolt had half the risk of getting PD than all other smolt groups. This is in accordance with findings by Kristoffersen et al. (2009), who demonstrated that autumn smolt have a higher risk of acquiring PD than other smolt groups. Smolt that are put to sea in spring have the benefit of a larger start weight and favorable conditions for growth and development of the immune system. 
In addition to the number of outbreaks, the effect of $\mathrm{PD}$ and vaccination on other production outcomes was evaluated. For all factors, PD outbreak had a negative influence on the outcomes. Thus, following a PD outbreak, the cumulative mortality, number of fish discarded at slaughter and amount of feed used per kg biomass increased, whereas the growth rate decreased. This is consistent with what was anticipated and what has been reported elsewhere (McLoughlin \& Graham 2007).

The positive effect of vaccination on cumulative mortality persisted when the control cohorts were also included in the analysis. Thus, the effect of vaccination is not only due to the overall reduced number of outbreaks, and vaccination will reduce mortality and number of fish discarded even in cases of PD outbreak. If all other factors are kept constant, the cumulative mortality at PD sites decreased from 22.5 to $15 \%$ if the fish were vaccinated. In comparison, the mean cumulative mortality for cohorts with PD outbreak was $22.6 \%$, and $11.7 \%$ for the controls without PD. Thus, vaccinating decreases the mortality of a PD outbreak almost to the same level as if the cohort had not experienced an outbreak. Similarly, the amount of discarded fish decreased from $2.74 \%$ for non-vaccinated fish to $1.28 \%$ for vaccinated fish, which is similar to the amount discarded in control cohorts without PD.

Evaluation of IPN vaccination using cumulative mortality as a measure of effect similarly shows that the losses due to IPN can be reduced if the smolt are vaccinated against IPN prior to an outbreak (Ramstad et al 2007).

Studies on the effect of vaccines against vibriosis have demonstrated positive effects on feed conversion rate and growth rate in vaccinated compared to non-vaccinated salmonid populations (Thorarinsson \& Powell 2006). A similar effect of PD vaccination could not be demonstrated in the present study at the chosen significance levels. As is discussed by Thorarinsson \& Powell (2006), this could be due to different vaccine formulation, genotype and species of fish.

Besides vaccination, many other factors determine the consequences of a PD outbreak. The present study shows that other diseases like IPN, HSMI, CMS and gill inflammation may have an influence on production outcomes under certain circumstances. However the effect varied and the meaning is therefore difficult to interpret. For example, whereas gill inflammation caused an increase in the amount of feed used per kg biomass produced, CMS or HSMI had the opposite effect. Studies specifically targeting these diseases should be conducted in order to clarify these results.

Density was also tested as a risk factor but was only included in the growth rate model, where the effect was small. This suggests that the differences in densities used for the studied populations do not influence the severity of disease following infection with PD.

During the study period, other PD-reducing actions were initiated as described. Presumably, these measures also played a role in decreasing the number of PD outbreaks and losses due to PD. Unfortunately the effects of these other measures are difficult to measure as data were not collected with the aim of such an evaluation. As these measures were just beginning to be implemented at the start of the study period, it is reasonable to assume that the effects should be seen most clearly in cohorts from later generations; therefore, generation was taken into account as a confounding factor in the models. In some of the models, there was some effect of generation, but in others this effect was negligible. As explained above, vaccination was a strong preventive factor, the power of which increased when the last 2 generations with only vaccinated cohorts were excluded (see the supplement).

In this study, locations farming rainbow trout were not included because they differ from Atlantic salmon farming locations in 2 important aspects with regards to $\mathrm{PD}$. The effects of $\mathrm{PD}$ on rainbow trout are considered to be different from those on Atlantic salmon, and locations farming rainbow trout did not take part in the PD-free project. Even though rainbow trout develop the same clinical signs, findings in field and challenge trials indicate that they are less susceptible to PD and that prevalence of pathological changes is lower in this species than in Atlantic salmon (Taksdal et al 2007). In addition, Norwegian fish farmers report that clinical outbreaks are less severe in rainbow trout than in Atlantic salmon, and they have not been using vaccination against PD in rainbow trout for this reason. However, since there are no indications that rainbow trout shed less virus than Atlantic salmon, all locations were included when calculating infection pressure. Further, the restrictions regarding movement apply without discrimination towards species.

In recent years, there has been an increase in number of rainbow trout locations reporting PD outbreaks (NVI PD outbreak statistics), and this is one reason why the total annual number of PD outbreaks has remained high, even though the number of outbreaks in Atlantic salmon farming sites has decreased. 
As the study was based on voluntary participation, biases towards cohort selection cannot be excluded. Cohorts were not randomly selected with regards to PD status, but there was little difference between numbers of PD outbreaks in included versus excluded cohorts and between the proportion of vaccinated cohorts in cases and controls. To address a possible bias regarding the difference in proportion of vaccinated cohorts, the analyses regarding production factors were performed on only PD case cohorts in addition to on all cohorts. This did not change the main results of the analysis, but some of the less important risk factors became non-significant, indicating either that the data set became too small or that the effect of PD overshadowed the other risk factors.

The difference in proportion of outbreaks between included and excluded cohorts was $5 \%$, which is too small a difference to pose as a bias. In this study field data from half of all cohorts actively farming Atlantic salmon in the endemic area during the study period were represented, which the authors believe to be representative of the entire Norwegian Atlantic salmon farming population in this area.

\section{CONCLUSIONS}

The number of PD outbreaks has been used by industry and stake-holders as an indicator for the effect of the strategy to control PD and, specifically, for the effect of vaccination. In this study, we have shown that vaccination against PD causes a decrease in the number of $\mathrm{PD}$ outbreaks and has a positive effect on other important production factors, especially cumulative mortality. We have also certified the negative effect of PD outbreaks on the same production factors. Thus, by using several different parameters for evaluating the effect of disease and risk factors, a more differentiated result is obtained. This is worth considering in future evaluations of vaccination and other control strategies.

Acknowledgements. The authors acknowledge all the farmers who took time to answer the questionnaire. The PD-free project is acknowledged for financial support for this study. Further, the authors thank N. Toft, University of Copenhagen for critical review of the statistical work presented in this manuscript.

\section{LITERATURE CITED}

Brun E (2001) A field study to evaluate vaccination against infectious pancreas necrosis in sea farmed Atlantic

Editorial responsibility: Nicholas Tolimieri, Seattle, Washington, USA salmon (Salmo salar L.) in Norway. MSc thesis, Norwegian Veterinary Institute, Oslo

Brun E (2003) Epidemiology. In: Skjelstad B, Brun E, Jensen I, Johansen LH, Midtlyng PJ, Rimstad E, Stagg R, Evensen $\varnothing$ (eds) IPN in salmonids - a review. VESO and FHL, Trondheim, p 51-67

> Duong QP (1984) On the choice of the order of autoregressive models: a ranking and selection approach. J Time Ser Anal 5:145-157

FKD (Fiskeri og kystdepartementet) (2007) Forskrift om sone for å hindre smitte og bekjempe pankreassjukdom hos akvakulturdyr. FOR 2007-11-20 nr 1315. Available at www.lovdata.no/cgi-wift/ldles?doc=/sf/sf/sf-200711201315.html

FKD (Fiskeriog kystdepartementet) (2008) Forskrift om omsetning av akvakulturdyr og produkter av akvakulturdyr, forebygging og bekjempelse av smittsomme sykdommer hos akvatiske dyr. FOR 2008-06-17 nr 819. Available at www.lovdata.no/cgi-wift/ldles?doc=/sf/sf/ sf-20080617-0819.html

Jansen MD, Taksdal T, Wasmuth MA, Gjerset B, Brun E, Olsen AB, Breck O, Sandberg M (2010) Salmonid alphavirus (SAV) and pancreas disease (PD) in Atlantic salmon, Salmo salar L., in freshwater and seawater sites in Norway from 2006 to 2008. J Fish Dis 33:391-402

Kristoffersen AB, Viljugrein H, Kongtorp RT, Brun E, Jansen PA (2009) Risk factors for pancreas disease (PD) outbreaks in farmed Atlantic salmon and rainbow trout in Norway during 2003-2007. Prev Vet Med 90:127-136

> McLoughlin MF, Graham DA (2007) Alphavirus infections in salmonids - a review. J Fish Dis 30:511-531

Norvax (2009) Pancreas disease in salmon and its control. Compact PD technical manual. Intervet, ScheringPlough Animal Health. Available at http://aqua.merckanimal-health.com/binaries/20671_Compact_PD_Tech nical_Manual_AW2_HR_FINAL_tcm127-208261.pdf

Pinheiro J, Bates D, DebRoy S, Sarkar D (2010) Nlme: linear and nonlinear mixed effects models. $\mathrm{R}$ package version 3.1-97. Available at www.cran.r-project.org

Poppe T, Rimstad E, Hyllseth B (1989) Pancreas disease in Atlanctic salmon (Salmo salar) postsmolts infected with infectious pancreatic necrosis virus (IPNV). Bull Eur Assoc Fish Pathol 9:83-85

Ramstad A, Romstad AB, Knappskog DH, Midtlyng PJ (2007) Field validation of experimental challenge models for IPN vaccines. J Fish Dis 30:723-731

Stanish WM, Taylor N (1983) Estimation of the intraclass correlation coefficient for the analysis of covariance model. Am Stat 37:221-224

> Taksdal T, Olsen AB, Bjerkås I, Hjortaas MJ, Dannevig BH, Graham DA, McLoughlin MF (2007) Pancreas disease in farmed Atlantic salmon, Salmo salar L., and rainbow trout, Oncorhynchus mykiss (Walbaum), in Norway. J Fish Dis 30:545-558

- Thorarinsson R, Powell DB (2006) Effects of disease risk, vaccine efficacy, and market price on the economics of fish vaccination. Aquaculture 256:42-49

Venables WN, Ripley BD (2002) Modern applied statistics with S, 4th edn. Springer, New York, NY

> Viljugrein H, Staalstrøm A, Molvær J, Urke HA, Jansen PA (2009) Integration of hydrodynamics into a statistical model on the spread of pancreas disease (PD) in salmon farming. Dis Aquat Org 88:35-44

Submitted: February 24, 2012; Accepted: May 23, 2012

Proofs received from author(s): November 16, 2012 